\title{
Fabrication and characterization of $\mathrm{HAp} / \mathrm{Al}_{2} \mathrm{O}_{3}$ composite cating on titanium substrate
}

\author{
Zhou-Cheng Wang, Yong-Jin Ni, Jin-Cong Huang \\ Department of Chemical and Biological Engineering, College of Chemistry and Chemical Engineering, Xiamen University, Xiamen, China. Correspondence \\ should be addressed to Zhou-Cheng Wang (zcwang@xmu.edu.cn). \\ Received July 5, 2008; revised September 28, 2008; accepted September 28, 2008
}

\begin{abstract}
$\mathrm{HAp} / \mathrm{Al}_{2} \mathrm{O}_{3}$ composite coating was fabricated onto micro-arc oxidized titanium substrate using a combination of electrophoretic deposition and reaction bonding process. SEM, EDS and XRD were employed to characterize the titanium substrate and as-prepared coatings. The interfacial bonding strength of the sintered composite coating was tested by shear strength testing experiment. Results show that the green form composite coating can be easily sintered with no cracks and decomposition at $850^{\circ} \mathrm{C}$, the bonding strength to the substrate is significantly improved compared with the single HAp coating.
\end{abstract}

Keywords: Hydroxyapatite; Composite coating; Electrophoretic deposition; Reaction bonding process

\section{INTRODUCTION}

Titanium and its alloys are widely used for dental and orthopedic implants, because of their high mechanical properties, chemical stability, and biocompatibility. Due to its poor osteoconductive properties, coating of bioactive hydroxyapatite $\left(\mathrm{Ca}_{10}\left(\mathrm{PO}_{4}\right)_{6}(\mathrm{OH})_{2}, \mathrm{HAp}\right)$, which has similar chemical and crystallographic structure to the main inorganic phase of human bone tissues, onto biomedical titanium implants has attracted widespread interest in the orthopaedics biomedical field [1].

Many techniques have been investigated for depositing HAp onto metallic implants, including plasma spray [2], thermal spray [3], sol-gel processing [4], electrolytic deposition [5] and electrophoretic deposition [6]. Among these techniques, plasma spraying is the most developed process and has been used in clinical practice; however, this process suffers from facts that it requires complex and costly equipment and being a line-of-sight process which is difficult to apply uniform coatings on implants with complex geometries.

Electrophoretic deposition (EPD) is a colloidal forming technique where charged, colloidal particles in a stable suspension are deposited onto a positively charged substrate by the application of electric field [7]. EPD has recently gained increasing interest in the processing of advanced ceramic materials and coatings not only because of its coast-effectiveness requiring simple apparatus, but also it offers important advantages in the deposition on substrates of complex geometry [8]. As for many ambient-temperature powder coating processes, the deposit is in the form of a loosely packed particles which must be subsequently densified by heating the coated implant to elevated temperatures [9]. Electrophoretic deposition of HAp coating onto metallic substrate has gained wide interest and previous researches have demonstrated that EPD is an attractive method for formation of biomedical implants and a number of advantages of this method have been suggested [10]. However, most of the reports demonstrated that bonding strength between HAp coating and titanium substrate is commonly low and far from the requirement for clinical application.

The main problem associated with the EPD process is the difficulty in the sintering of the coatings. First, high sintering temperature is required for full densification of the green coatings [9]. Lower sintering temperature leads to weakly bonded and lowly-densified coatings, whereas higher temperature can result in degradation of the metal substrate and decomposition of HAp coating. Decomposition of the HAp coating is undesirable as it leads to an enhanced in vivo dissolution rate. Sintering temperatures ideally should be below $1000^{\circ} \mathrm{C}$ [9]. Second, the thermal expansion coefficient of titanium substrate is much lower than that of HAp $\left(\alpha_{\mathrm{Ti}}=8.7 \times 10^{-6} / \mathrm{K}, \alpha_{\mathrm{HAp}}=13.6 \times 10^{-6} / \mathrm{K}\right)$, so large thermal contraction mismatch would arise and tend to induce the formation of cracks when cooled from the elevated temperatures; besides, a significant firing shrinkage during sintering will lead to the formation of cracks in coatings as well.

In the present work, reaction bonding $\mathrm{Al}_{2} \mathrm{O}_{3}$ with relatively lower thermal expansion coefficient $\left(\alpha_{\mathrm{Al} 2 \mathrm{O} 3}=8.3 \times 10^{-6} / \mathrm{K}\right)$ was introduced into the HAp coating to shorten the thermal expansion coefficient difference with the titanium substrate. Meanwhile, the reaction bonding process would overcome problems caused by the firing shrinkage during sintering [7]. Both the two advantages have been proved to be beneficial in avoiding the formation of cracks and improvement of bonding strength of ceramic coatings [11] 
Surface modification of the titanium substrate was also concerned. Chemically stable $\mathrm{TiO}_{2}$ can act as a bonding layer and chemical barrier, which improves the interfacial bonding, and prevent in vivo release of metal ions [12]. Among the methods used to produce the oxide layer on titanium substrate, the micro-arc oxidation (MAO) method has gained much interest, where anticorrosive and rough oxide coatings can be easily fabricated [13-14]. Rough morphology has been proved to be beneficial in mechanically anchoring the as-deposited coating [15]. So MAO surface modification was done prior to the deposition of composite coating.

\section{EXPERIMENTAL}

Commercially available titanium plates which were shaped in a size of $30 \mathrm{~mm} \times 10 \mathrm{~mm} \times 0.8 \mathrm{~mm}$, were used as the substrate materials. All the specimens were mechanically polished with $\mathrm{SiC}$ water-proof abrasive papers. Then they were degreased in a certain base solution and pickled in an acid solution containing $100 \mathrm{~mL} / \mathrm{L} \mathrm{HF}$ and $300 \mathrm{~mL} / \mathrm{L} \mathrm{HNO}_{3}$. After that, the specimens were treated with $\mathrm{MAO}$ in a sulfate solution. A platinum plate was used as the counter electrode.

For preparation of the EPD suspension, HAp and Al particles with an average particle size of $0.5 \mu \mathrm{m}$ were dried previously and dispersed in absolute ethanol. Drops of nitrate were used to adjust the $\mathrm{pH}$ value of the suspension to 4-5 approximately. Then the suspension was stirred in an ultrasonic agitator for 1 hour and aged for 1 day to allow full charging of the particles dispersed. Prior to the deposition, the suspension was again stirred in the ultrasonic agitator for $30 \mathrm{~min}$. EPD was carried out using applied voltages in the range $30-40 \mathrm{~V}$ for $30 \mathrm{~s}$. Two parallel stainless steel plates were used as the anodes. The deposited specimens were dried in air and then stored in a drying container.

The heat treatment was done in a tubular electric resistance furnace. The furnace was heated at a rate of $5^{\circ} \mathrm{C} / \mathrm{min}$ to $660^{\circ} \mathrm{C}$ and held at this temperature for 2 hours to allow the occurrences of melting and oxidation of $\mathrm{Al}$ particles. The temperature was then increased at

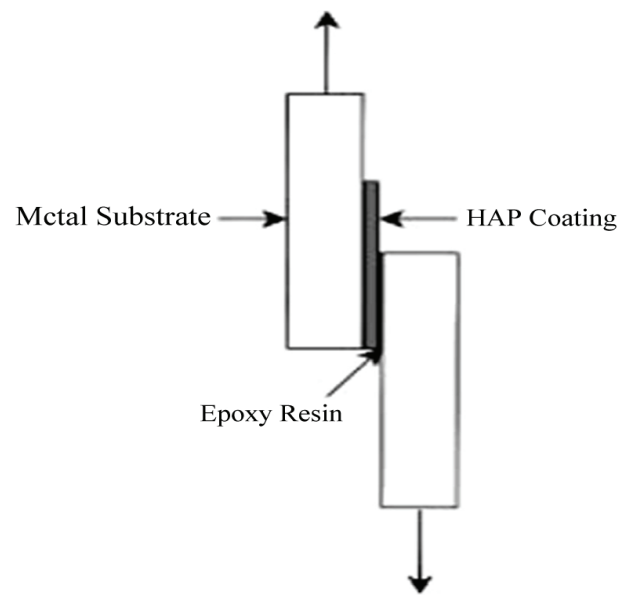

Figure 1. Schematic diagram of bonding strength testing. $5^{\circ} \mathrm{C} / \mathrm{min}$ to $850^{\circ} \mathrm{C}$ or $900^{\circ} \mathrm{C}$ and held for 2 hours for sintering. At last, the furnace was cooled in a rate of $1{ }^{\circ} \mathrm{C} / \mathrm{min}$ to room temperature. During the treatment, Ar atmosphere of high purity was controlled in a proper velocity to flow through the tube to protect the substrates from excessive oxidation in elevated temperatures.

The surface and cross-sectional morphologies of the MAO titanium and as-prepared coatings was observed by LEO1530-FESEM (Germany). The element composition of the composite coating was analyzed through EDS (Oxford, England) attached to the FESEM. The phase composition and thermal stability of the composite coating were analyzed by X-ray diffraction (Panalytical X'pert, Philips).

The interfacial bonding strength was tested by shear strength testing experiment according to ASTM-F1044 standard. This test relies on a bonding agent to remove the coating with applied shear force as shown in Figure 1. The value of the bonding strength can be calculated from the fracture force over the stressed area.

\section{RESULTS AND DISCUSSION}

Many researches have demonstrated that surface modify-

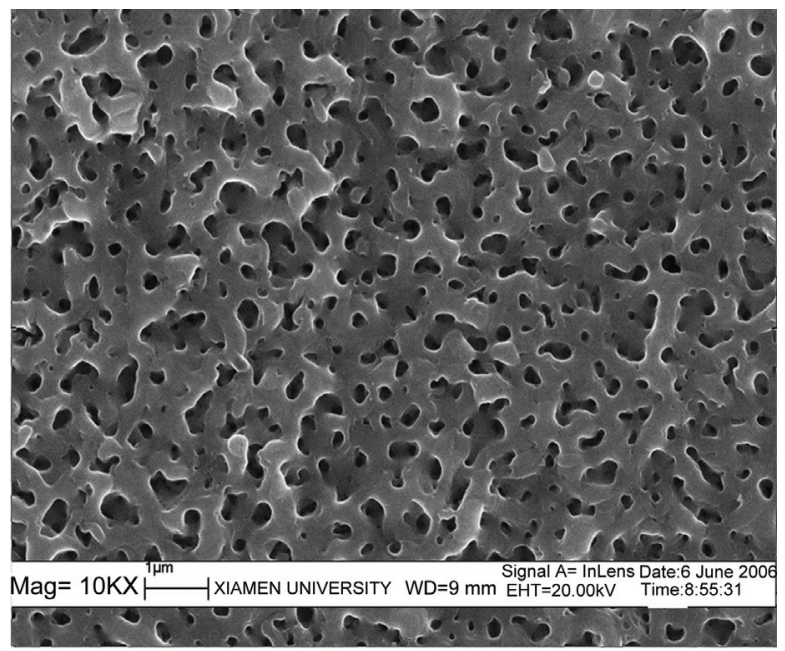

Figure 2.SEM images of the surface morphology of MAO treated titanium.

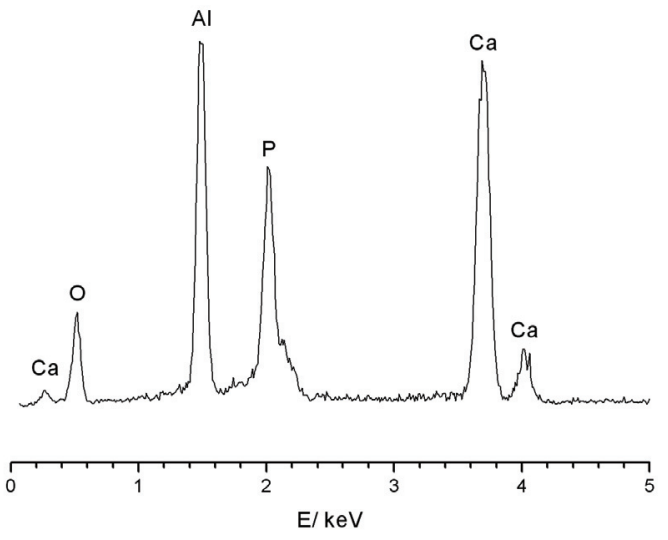

Figure 3.EDS spectrum of the composite coating 


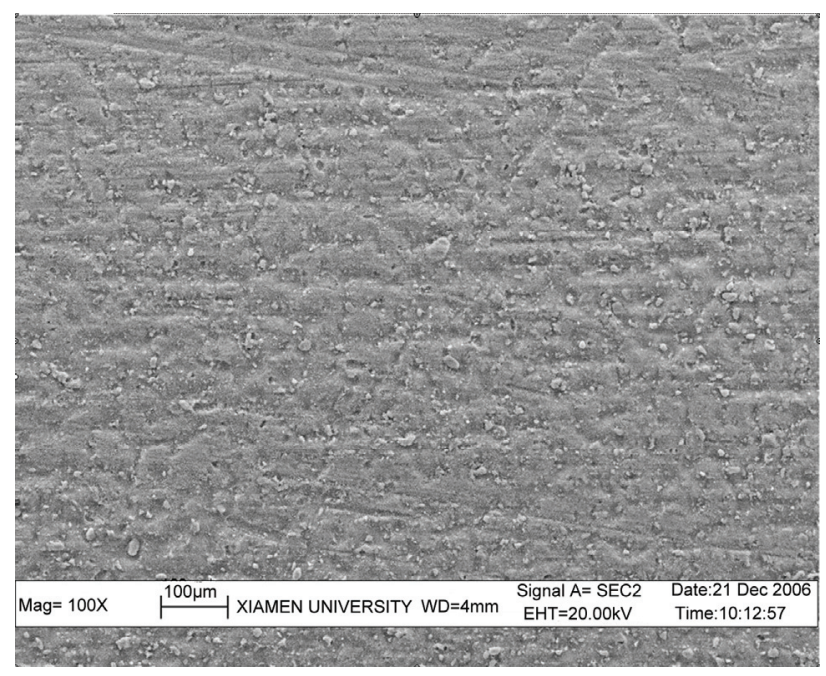

(a)

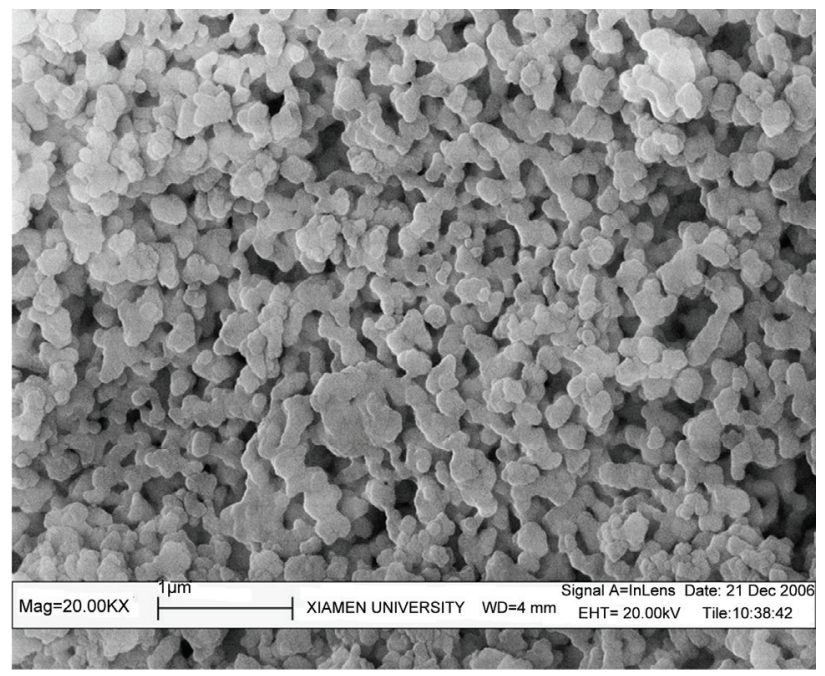

(b)

Figure 4. SEM images of the surface morphology of $\mathrm{HAp} / \mathrm{Al}_{2} \mathrm{O}_{3}$ composite coating sintered at $850^{\circ} \mathrm{C}$. (a: $\left.\times 100 ; \mathrm{b}: \times 20,000\right)$.

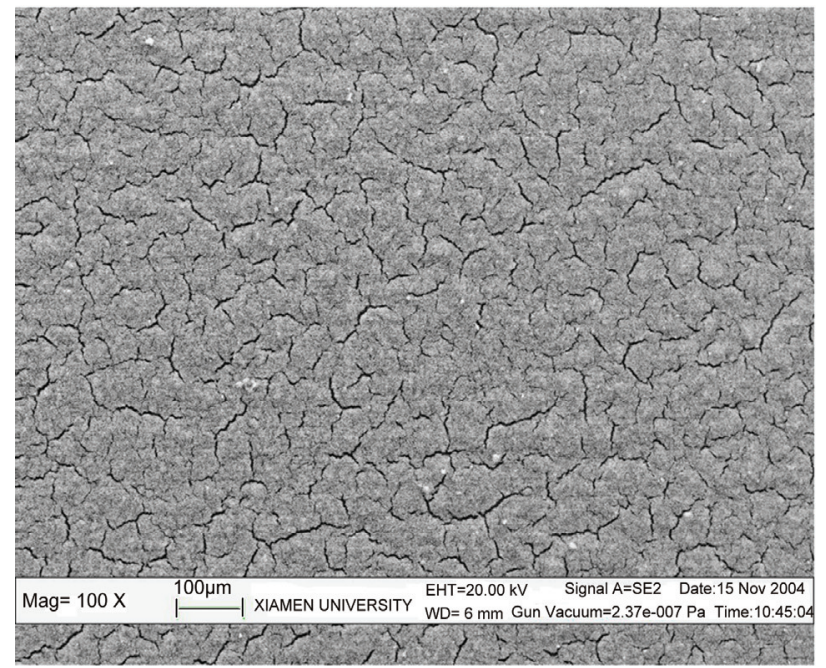

(a)

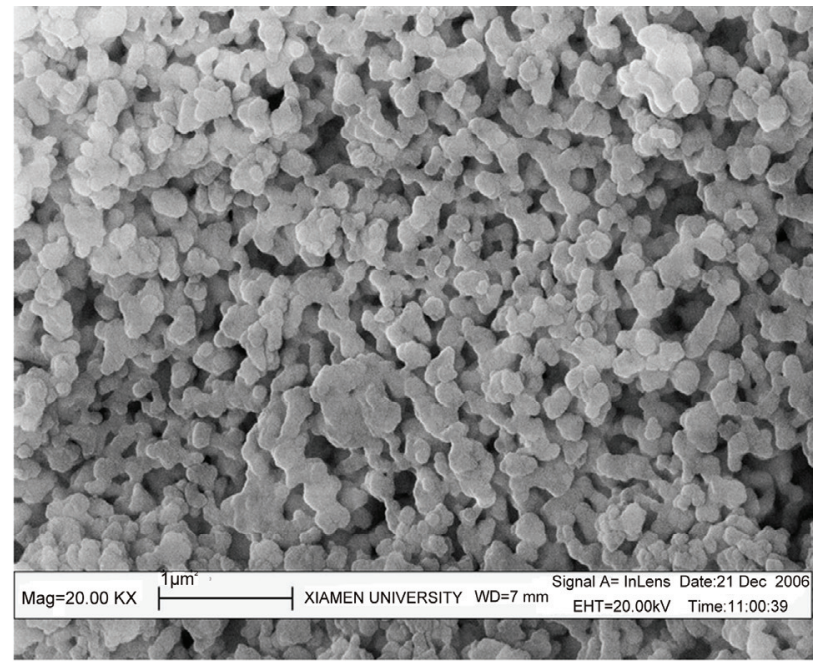

(b)

Figure 5. SEM images of the surface morphology of single HAp coating sintered at $850^{\circ} \mathrm{C} .(\mathrm{a}: \times 100 ; \mathrm{b}: \times 20,000)$.

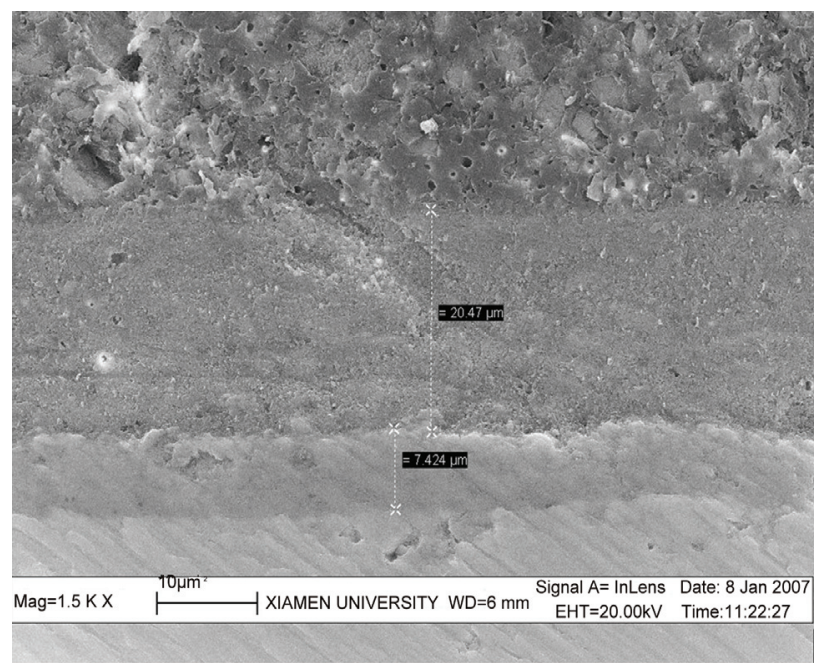

Figure 6. Cross-sectional morphology of $\mathrm{HAp} / \mathrm{Al}_{2} \mathrm{O}_{3}$ composite coating sintered at $850^{\circ} \mathrm{C}$.

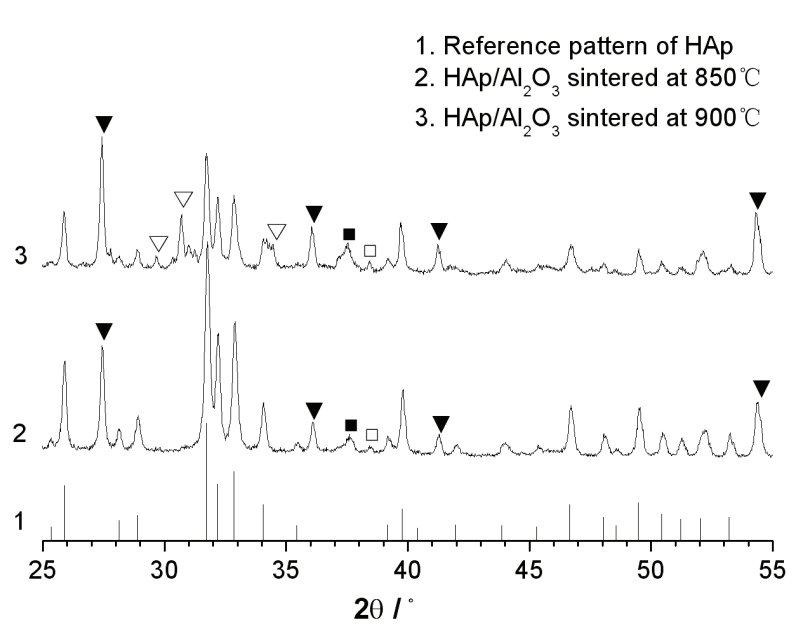

Figure 7. XRD patterns of $\mathrm{HAp} / \mathrm{Al}_{2} \mathrm{O}_{3}$ composite coating. ( $\boldsymbol{\nabla}$ : $\mathrm{TiO}_{2}$ (Rutile); - : Cubic-Al $\mathrm{O}_{3} ; \square: \mathrm{Al} ; \nabla:$ Decomposition products; The others: HAp) 
cation is essential to guarantee coating adhesion to metallic substrate [14]. MAO is an advance coating process for forming oxide layer on some anodic metal substrate which is accompanied by visible plasma-like sparking at the anode surface [13]. Prior to EPD of the composite coating, the titanium substrate was treated by MAO in a sulfate solution under constant current density of 50 $\mathrm{mA} / \mathrm{cm}^{2}$. Surface morphology in Figure 2 shows that the oxide film fabricated is rough and porous, which has been proved to be beneficial for mechanically anchoring the as-deposited coating [15].

The green form of $\mathrm{HAp} / \mathrm{Al}$ composite coating was co-deposited onto the titanium substrate from a suspension containing $10 \mathrm{~g} / \mathrm{L}$ HAp and $10 \mathrm{~g} \cdot \mathrm{L}$ Al particles using an applied voltage of $30 \mathrm{~V}$ for $30 \mathrm{~s}$. The chemical compositions of the composite coating were determined through EDS element analysis. Relating spectrum is shown in Figure 3. The results show that elements Al, $\mathrm{Ca}, \mathrm{P}$ and $\mathrm{O}$ are all present in the composite coating, which confirms that the co-deposition of HAp and Al under the present condition is feasible. Quantitative analysis based on the spectrum shows that the weight percentage of $\mathrm{Al}$ in the composite coating was about $17.5 \%$, and the $\mathrm{Ca} / \mathrm{P}$ mole ratio was about 1.70 , which is approximately equal to the stoichiometric ratio of HAp, and this confirms the chemical stability of HAp in the suspension.

Figure 4 shows the surface morphology of the as-prepared $\mathrm{HAp} / \mathrm{Al}_{2} \mathrm{O}_{3}$ composite coating after sintered at $850^{\circ} \mathrm{C}$. The surface morphology of single HAp coating fabricated under the same conditions is also shown in Figure 5 as comparison. As shown in Figure 4 (a), no cracks were observed from the surface of the composite coating; while for the single HAp coating as shown in Figure 5 (a), numerous cracks were found because of the firing shrinkage during sintering. Figure 4 (b) shows that the composite coating was well sintered. It is obvious that particles in the composite coating bond with each other and grain size grows; however, for the single HAp coating shown in Figure 5 (b), most particles appear to remain stand-alone, bonding among the particles is not as full as in the composite coating and there is nearly no growth of grain size. It can be excluded that the sintering property is greatly improved by the addition of Al to the green form coating. The irregular shape of grains in the composite coating implies the presence of liquid phase during sintering which is known to be beneficial in promoting the mass transport and bonding among grains. The volume expansion associated with the oxidation reaction of $\mathrm{Al} \rightarrow \mathrm{Al}_{2} \mathrm{O}_{3}$ partially compensates for the sintering shrinkage and prevents the formation of cracks.

Figure 6 shows the cross-sectional morphology of the composite coating after sintered at $850^{\circ} \mathrm{C}$, which presents an impression of a layered interfacial structure. A dense oxide layer, which came from a composite oxidation of MAO and heating oxidation, is present between the composite coating and substrate. The oxide layer acts as a bonding layer to bond the composite coating and sub- strate together, which is able to improve the interfacial bonding strength. Besides, the dense oxide layer is beneficial in preventing the ion release from the metallic substrate [13].

Figure 7 shows XRD patterns of the sintered coatings. All the diffraction patterns confirm the presence of rutile- $\mathrm{TiO}_{2}$ as the inner bonding layer shown in Figure 6, and HAp as the main phase in the composite coating. The sharp and clear reflections corresponding to HAp confirm the phase purity and high crystallinity which is critical for in vivo stability of the implants. The confirmation of the existence of $\mathrm{Al}_{2} \mathrm{O}_{3}$ in the HAp coating puts the lowering the thermal expansion coefficient of the composite coating into effect and contributes to the increase of interfacial bonding strength.

The thermal stability of the as-prepared composite coating was also studied to determine a proper heat treatment condition. At the sintering temperature of $850^{\circ} \mathrm{C}$, no signs of HAp decomposition can be found in the relating XRD pattern. While sintered up to $900^{\circ} \mathrm{C}$, several peaks (marked by " $\nabla$ ") of new phase arise in the corresponding XRD pattern and imply the thermal decomposition of HAp phase; but reflections characteristic for HAp still well match its reference pattern, which suggests that decomposition degree of HAp is not serious. Hence, in order to guarantee the chemical and structural integrity of HAp and its in vivo properties, the sintering temperature should necessarily be controlled to be below $900^{\circ} \mathrm{C}$.

Interfacial bonding strength of the as-prepared $\mathrm{HAp} / \mathrm{Al}_{2} \mathrm{O}_{3}$ composite coating was tested. Results are shown in Tab.1 where each value represents a statistic average of three test data. Obviously the bonding strength of $\mathrm{HAp} / \mathrm{Al}_{2} \mathrm{O}_{3}$ composite coating is commonly higher than that of single HAp coating under the two sintering temperature. The improvement of interfacial bonding can mainly be attributed to the application of reaction bonding process. The process overcame the cracking problem and improved the sintering property of the coating as analyzed above. On the other hand, the formation of reaction bonding $\mathrm{Al}_{2} \mathrm{O}_{3}$ with relatively lower thermal expansion coefficient shortens the thermal expansion coefficient difference between the coating and the titanium substrate, and improves the interfacial bonding as well.

\section{CONCLUSION}

Rough and porous oxide film, which has been proved to be beneficial in mechanically anchoring the as-deposited coating, was fabricated on titanium substrate through the MAO technique. The electrophoretic co-deposition of HAp and Al powder was achieved successfully to form HAp/Al composite coating. The sintering temperature of the composite coating should be controlled to be below $900^{\circ} \mathrm{C}$ due to the thermal decomposition of HAp phase. A crack-free and adhesive $\mathrm{HAp} / \mathrm{Al}_{2} \mathrm{O}_{3}$ composite coating was then successfully fabricated using the combination of electrophoretic deposition and reaction bonding proc- 
ess. The reaction bonding process promotes the coating's sintering densification and improves the substrate's oxidation resistance during the heat treatment. In comparison with the single HAp coating, the $\mathrm{HAp} / \mathrm{Al}_{2} \mathrm{O}_{3}$ composite coating exhibits much higher bonding strength.

\section{ACKNOLEDGEMENT}

Dr Zhou-Cheng Wang thanks for the financial support from Natural Science Foundation of China (20573086), National Key Technology R\&D Program of China (2007BAE05B04) and National Basic Research Program of China (973 Program) (2007CB935603).

\section{REFERENCES}

[1] M. Wei, A. J. Ruys, M. V. Swain, B. K. Milthorpe, C. C. Sorrell, "Hydroxyapatite-coated metals: interfacial reactions during sintering," J. Mater. Sci.: Mater. Med., vol. 16, pp. 101-106, February 2005.

[2] M. M. Andin, L. S. Ozyegin, F. N. Oktar, E. Z. Erkmen, O. Anzabi, K. Gross, "Plasma sprayed zirconia-hydroxyapatite composite coatings," Key Engineering Materials, vol. 309-311, pp. 631-634, January 2006.

[3] H. Li, K. A. Khor, P. Cheang, "Impact formation and microstructure characterization of thermal sprayed hydroxyapatite/titania composite coatings," Biomaterials, vol. 24, pp. 949-957, March 2003.

[4] H. W. Kim, Y. H. Koh, L. H. Li, S. Lee, H. E. Kim, "Hydroxyapatite coating on titanium substrate with titania buffer layer processed by sol-gel method," Biomaterials, vol. 25, pp. 2533-2538, June 2004

[5] C. M. Lin, S. K. Yen, "Characterization and bond strength of electrolytic $\mathrm{HA} / \mathrm{TiO}_{2}$ double layers for orthopedic applications," J. Mater. Sci.: Mater. Med., vol. 15, pp. 1237-1246, November 2004.

[6] L. Besra, M. Liu, "A review on fundamentals and applications of electrophoretic deposition (EPD)," Progress in Materials Science, vol. 52, pp. 1-61, January 2007.

[7] P. Sarkar, D. De, H. Rho, "Synthesis and microstructural manipulation of ceramics by electrophoretic deposition," J. Mater. Sci., vol. 39, pp. 819-823, February 2004.

[8] A. Khor, H. Li, K. P. Cheang, "Processing-microstructure-property relations in HVOF sprayed calcium phosphate based bioceramic coatings," Biomaterials, vol. 24, pp. 2233-2243, June 2003.

[9] M. Wei, A. J. Ruys, M. V. Swain, "Precipitation of hydroxyapatite nanoparticles: Effects of precipitation method on electrophoretic deposition," J. Mater. Sci.: Mater. Med., vol. 16, pp. 319-324, April 2005.

[10] J. Ma, C. H. Liang, L. B. Kong, C. Wang, "Colloidal characterization and electrophoretic deposition of hydroxyapatite on titanium substrate," J. Mater. Sci.: Mater. Med., vol. 14, pp. 797-801, September 2003.

[11] Z. Wang, P. Xiao, J. Shemilt, "Fabrication of composite coatings using a combination of electrochemical methods and reaction bonding process," J. European Ceramic Society, vol.20, pp. 1469-1473, September 2000.

[12] H. Kurzweg, R. B. Heimann, T. Troczynski, M. L. Wayman, "Development of plasma-sprayed bioceramic coatings with bond coats based on titania and zirconia," Biomaterials, vol. 19, pp. 1507-1511, August 1998.

[13] L. H. Li, Y. M. Kong, H. W. Kim, Y. W. Kim, H. E. Kim, S. J. $\mathrm{Heo}$, "Improved biological performance of $\mathrm{Ti}$ implants due to surface modification by micro-arc oxidation," Biomaterials, vol. 25, pp. 2867-2875, June 2004.

[14] X. Nie, A. Leyland, A. Matthews, "Deposition of layered bioceramic hydroxyapatite/TiO2 coatings on titanium alloys using a hybrid technique of micro-arc oxidation and electrophoresis," Surface and Coatings Technology, vol. 125, pp. 407-414, March 2000.

[15] L. A. de Sena, M. C. de Andrade, A. M. Rossi, "Hydroxyapatite deposition by electrophoresis on titanium sheets with different surface finishing," J. Biomedical Materials Research, vol. 60, pp.1-7, April 2002. 